\title{
Program Pelatihan Jurnalistik Sekolah di MA NU Tengguli Kecamatan Bangsri Kabupaten Jepara
}

\author{
Murniati, Khoirul Muslimin, Abdul Wahab, Mahfudlah Fajrie \\ Universitas Islam Nahdlatul Ulama Jepara \\ murniati@unisnu.ac.id
}

Submitted: 29 March 2019; Revised: 22 April 2019; Accepted: 27 July 2019

Key word:

Journalistic

school;

journalistic

skills; reportage;

press release;

wall magazine
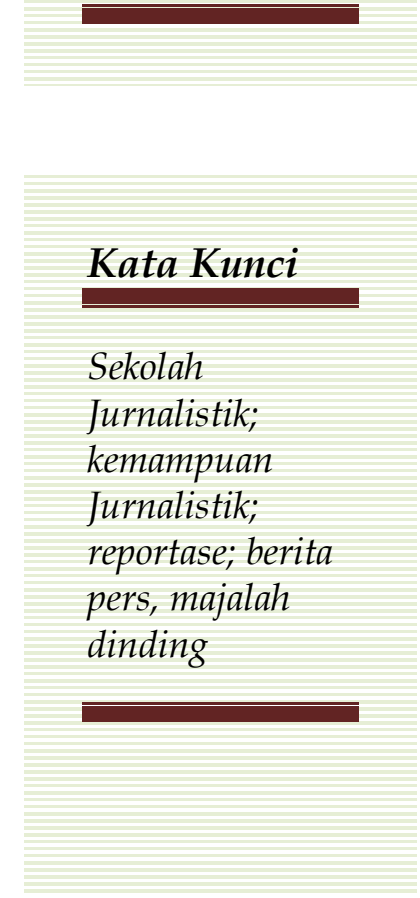

\section{Abstract}

The journalistic school service activities were carried out at MA NU Tengguli. This school has students who have the potential to write, both writing short stories, poetry, and poetry but are not structured and do not meet the standard rules of writing. Besides the ability to write news or opinions and articles not yet seen. The aim of this services is to increase the journalism skill of the students there. Based on the analysis, the activities carried out are 1) News writing training; 2) Training on making press releases; 3) Training on layout and editing of scripts. The results obtained are 1) Students are able to arrange interview questions and write in the form of reportage; 2) students are able to make news; 3) students are able to make press releases and understand the functions of public relations; 4) students are able to make simple layouts for wall magazines and do editing of scripts.

\section{Abstrak}

Kegiatan pengabdian sekolah jurnalistik dilakukan di MA NU Tengguli. Sekolah ini memiliki siswa yang mempunyai potensi menulis, baik menulis cerpen, puisi, dan sajak namun belum terstruktur dan belum memenuhi kaidah menulis yang baku. Selain itu kemampuan menulis berita ataupun opini serta artikel belum terlihat. Tujuan dari pengabdian adalah meningkatkan kemampuan jurnalistik siswa. Berdasarkan analisis awal, kegiatan yang dilakukan adalah 1) Pelatihan penulisan berita; 2) Pelatihan pembuatan press release; 3) Pelatihan layout dan editing naskah. Hasil yang didapat adalah 1) Siswa mampu menyusun pertanyaan wawancara dan menuliskan dalam bentuk reportase; 2) siswa mampu membuat berita; 3) siswa mampu membuat press release dan memahami fungsi kehumasan; 4) siswa mampu membuat layout sederhana untuk majalah dinding dan melakukan editing naskah. 


\section{PENDAHULUAN}

Budaya membaca dan menulis di Indonesia secara umum masih sangat rendah, hal ini membenarkan data tentang budaya literasi boleh dikatakan masih minim. Penelitian yang dilakukan oleh Central Connecticut State Univesity pada Maret 2016, Indonesia menduduki peringkat ke 60 dari 61 negara yang masih memiliki budaya baca tulisnya rendah (Nopilda \& Kristiawan, 2018). Fenomena ini cukup memprihatinkan, karena dari membaca, seseorang akan mudah mendapatkan pengetahuan.

Literasi juga tidak bisa dilepaskan dari wahyu dari Allah SWT yang pertama kali diturunkan kepada Nabi Muhammad SAW dengan perintah membaca (Q.S. Al-Alaq 1-5). Penegasan perintah Allah SWT dalam surat al-Alaq 1-5 tersebut mengandung pelajaran betapa pentingnya budaya baca untuk memperoleh pengetahuan dan literasi adalah kemampuan untuk membaca, menulis, menyimak, dan berbicara (Anggraini, 2016).

Tujuan pendidikan nasional yang tercantum dalam UU. RI. No. 20 tentang Sistem Pendidikan Nasional, bahwa "Pendidikan Nasional bertujuan untuk berkembangnya potensi peserta didik agar menjadi manusia yang beriman dan bertaqwa kepada Tuhan Yang Maha Esa, berakhlaq mulia, sehat, berilmu, cakap, kreatif, mandiri dan menjadi warga yang demokratis serta bertanggung jawab", mengandung maksud, bahwa manusia Indonesia khususnya siswa adalah merupakan produk yang oleh lembaga pendidikan akan dibentuk dan diolah menjadi manusia yang berilmu, berakhlaq mulia, sehat jasmani dan rohani serta kreatif dan mandiri (Indonesia, 2003). Berdasarkan hal ini maka pendidikan yang berbasis literasi sudah selayaknya dibiasakan dalam dunia pendidikan dan bukan sesuatu hal yang aneh jika budaya literasi berawal dari budaya dipaksa membaca sehingga terbentuk budaya malu jika tidak membaca (Suragangga, 2017).

Lembaga pendidikan bisa dijadikan sarana yang strategis untuk mendorong budaya membaca dan menulis. Siswa diajari untuk bisa mengasah minimal tiga kecerdasan; kecerdasan kognisi, afeksi dan psikomotorik. Ketiga model kecerdasan baik kognisi, afeksi maupun psikomotorik bermuara pada bagaimana seseorang pandai membaca dan mengambil pelajaran dalam berkehidupan.

Seiring dengan kemajuan ilmu pengetahuan dan teknologi, dimana di era 4.0 generasi muda dituntun untuk bisa mengadaptasi dengan cepat berbagai gejolak sosial akibat kecanggihan media internet. Hal tersebut sudah dimulai sejak 
tahun 90-an dimana media massa mainstream sudah mulai ditinggalkan akibat kecanggihan media internet. Media massa baik cetak maupun elekronika mempunyai dampak yang cukup signifikan dalam mempengaruhi pola fikir dan perilaku masyarakat penggunanya (Fitryarini, 2017).

Media massa baik cetak maupun elektronika di era kontemporer seperti sekarang ini cukup signifikan dalam membangun, membanting imajinasi, opini bahkan citra seseorang dalam mempengaruhi massa. Eksistensi media bisa mengkonstruksi mindset pembacanya untuk berbuat baik atau tidak (Wahid, 2014). Literasi media menjadi kata kunci dalam era modern ini. Manusia telah menjadikan teknologi informasi dan komunikasi sebagai bagian dari kehidupannya (Supratman \& Wahyudin, 2017), sehingga keterampilan dalam berliterasi dibutuhkan untuk tidak tertinggal jauh dengan derasnya arus komunikasi.

Kepiawaian dalam mengemas pesan yang bermartabat di media massa baik cetak maupun elektronika mutlak dibutuhkan agar mental menulis generasi muda sekarang juga mempertimbangkan sisi etika dan estetika menulis pesan. Jika hal ini dikuasai oleh generasi muda, maka maraknya budaya hoax yang akhir-akhir ini berkembang bisa dieliminir. Adanya buzzer yang diorganisir sedemikian rupa untuk kepentingan tertentu dalam memengaruhi massa mengharuskan semua pihak berempati dan prihatin agar generasi muda kita tidak terjangkit budaya menulis berita yang berbau hoax.

Upaya yang dilakukan pemerintah untuk memberantas pengiriman berita hoax melalui Kementerian Kominfo yaitu dengan memblokir 11 situs yang dianggap memproduksi konten negatif dan cenderung mengeluarkan ujaran kebencian harus direspon positif semua pihak agar generasi muda kita tidak terjangkiti patologi sosial berupa penyebaran berita hoax.

Dewasa muda atau remaja usia SMA adalah generasi yang dapat mengakses internet dan berita khususnya melalui media sosial dengan begitu cepat. Diharapkan siswa usia SMA dapat menyaring berita berbekal dengan keterampilan literasi (Gumilar, 2017). Berdasarkan latar belakang ini, tim pengabdi memilih MA NU Tengguli yang merupakan salah satu lembaga pendidikan swasta dalam naungan Lembaga Pendidikan Ma'arif Jepara yang berada di Kec. Bangsri Jepara, tepatnya berada di Jl. Raya RT.02 RW. 06 Tengguli Bangsri KM.01 Kode Pos 59453 yang notabene sekolah menengah atas yang secara 
geografis terletak di desa, namun para siswanya mempunyai akses informasi yang luas dari sosial media yang dimiliki. Selain itu, siswa-siswanya memiliki potensi kemampuan menulis. Hal ini ditunjukkan dari adanya majalah dinding di sekolah. Majalah dinding ini berisi beberapa cerpen, sajak dan puisi. Akan tetapi yang berkaitan dengan konten berupa informasi (berita) belum tersaji. Penelusuran tim pengabdi melalui kegiatan survey awal menunjukkan bahwa siswa memiliki keinginan untuk bisa menulis berita dan melakukan pekerjaan jurnalisme seperti kegiatan reportase di lapangan, kegiatan menghubungi narasumber untuk mendukung pemberitaan belum pernah dilakukan dan memang para siswa belum bisa melakukan dikarenakan dari pihak sekolah belum pernah melakukan pendampingan akan pentingnya pelatihan dan pengawalan kemampuan kejurnalistikan. Kendala yang tak kalah pentingnya dikarenakan kurangnya sarana dan prasarana pendukung serta belum dibekalinya skill menulis yang sistematis dari pihak sekolah.

Kondisi tersebut benar adaanya setelah tim pengabdi melakukan penelusuran langsung ke lapangan. Kondisi sarana prasarana yang mendukung kreatifitas siswa terhadap budaya membaca dan menulis sangat minim. Hal ini dapat diluhat dari belum disediakannya tempat yang layak Mading (Majalah Dinding) sebagai tempat siswa siswi mengekspresikan kemampuan dalam menulis.

Sebagai ilustrasi kondisi sekolah MA NU Tengguli, tim pengabdi akan memaparkan beberapa foto pendukung bahwa memang belum ada fasilitas sarana prasarana yang mendukung kegiatan jurnalisme dilakukan.

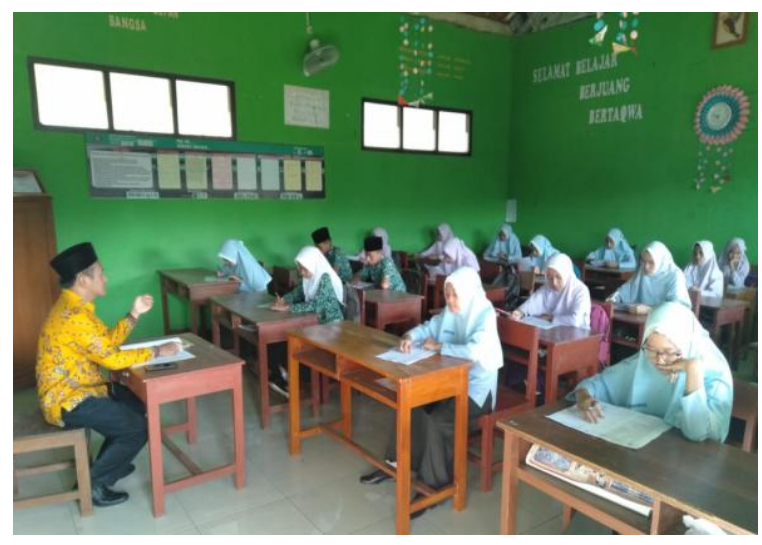

Gambar 1. Kondisi pembelajaran MA NU Tengguli

Gambar tersebut menunjukkan belum adanya Mading (Majalah Dinding) di kelas serta menggambarkan bahwa MA NU Tengguli adalah yang belum mempunyai sekedar majalalah dinding (Mading) dan belum mempunyai lembaga pers sekolah. Hal ini disebabkan karena tidak tersedianya tenaga kependidikan dilingkungan madrasah yang mempunyai kemampuan jurnalistik serta belum adanya sarana dan pra sarana pendukung lainnya. 
Rendahnya minat baca tulis pada siswa juga menjadi kendala tersendiri.

\section{Menurut Kepala MA NU Tengguli}

Soh Hadi, terdapat 30 siswa MA NU Tengguli yang sebenarnya sudah mempunyai keinginan untuk menulis fiksi, cerpen dan puisi, tetapi untuk menulis yang bersifat reportase (berita peliputan), artikel dan opini para siswa belum mempunyai bekal menulis. Hal tersebut menunjukkan adanya kebutuhan sebuah pelatihan jurnalistik, supaya tradisi menulis yang baik dan terarah bisa terealisasi.

Fakultas Dakwah Komunikasi kemudian melakukan kerjasama dengan MA NU Tengguli melalui program sekolah binaan berbasis penguatan Prodi untuk menjawab persoalan kejurnalistikan. Persoalan mitra sebagai berikut:

Aspek potensi lokal:

1. Lokasi MA NU yang terletak agak pedalaman dan lokasinya jauh dari kota kabupaten, menyebabakan agak susahnya akses informasi yang berupa media cetak surat kabar.

2. Belum adanya majalah dan buletin berkala yang di terbitkan olel LP Ma'arif NU Kab. Jepara sehingga akses informasi yang berkaiatan dengan edukasi belum begitu menunjang.

3. Siswa belum mempunyai skill menulis
4. Belum pernah mengadakan pelatihan jurnalistik

5. Belum terbentuk lembaga pers siswa

6. Belum mempunyai majalah sekolah

\section{Aspek Manajerial}

1. Manajemen pengelolaan media belum tersedia

2. Dibutuhkan rekayasa sosial tentang kesadaran literasi media

3. Dibutuhkan pelatihan jurnalistik

4. Dibutuhkan pembentukan lembaga pers sekolah

5. Dibutuhkan majalah sekolah untuk menunjang kebutuhan referensi membaca

Dari gambaran diatas dapat diidentifikasi hal-hal yang akan dilakukan dalam kegiatan pengabdian sebagai berikut:

1. Upaya yang dilakukan untuk memberdayakan siswa di lingkungan MA NU Tengguli, Kec. Bangsri, Kab. Jepara.

2. Cara menumbuhkan skill jurnalistik pada siswa di lingkungan MA NU Tengguli, Kec. Bangsri, Kab. Jepara.

3. Cara mewujudkan adanya media majalah berkala di MA NU Tengguli, Kec. Bangsri, Kab. Jepara.

\section{METODE}

Kegiatan PKM sekolah binaan ini dilakukan dengan metode kegiatan sebagai berikut: 
1. Sosialisasi Awal

Pada sosialisasi awal ini, tim PKM

Sekolah Binaan akan bersilaturahmi ke

MA NU Tengguli guna menggali informasi tentang situasi dan kondisi mitra, dimana diharapkan akan terjadi simbiosis mutualisme antara tim PKM sekolah binaan UNISNU Jepara dengan mitra.

2. Pelaksanaan Kegiatan

Kegaitan yang dilakukan tim pengabdi adalah pelatihan jurnalistik dan pembentukan majalah sekolah.

\section{Partisipasi mitra}

Mitra berpartisipasi sebagai peserta pelatihan, dan mitra terlibat langsung dalam pembuatan lembaga pers siswa dan pembentukan tim redaksi majalah sekolah serta mitra menindaklanjuti adanya majalah sekolah yang terbit secara berkala.

\section{Evaluasi}

Pada akhir kegiatan, akan diadakan evaluasi. Evaluasi dilakukan untuk mengetahui tingkat keberhasilan program sekolah binaan. Evaluasi juga dilakukan untuk mengetahui hambatan dan kesulitan yang dihadapi selama kegiatan dan seberapa jauh tingkat keberhasilan program dan tawaran solusi alternatif.

\section{HASIL}

Hasil yang dicapai oleh Fakultas Dakwah dan Komunikasi Prodi Komunikasi Penyiaran Islam dalam program pengabdian kepada sekolah binaan di MA NU Tengguli dengan title acara adalah:

1. Pelatihan Teknik Menulis Berita

Pelatihan Teknik Menulis Berita dilaksanakan pada hari Rabu, tanggal 30 Mei tahun 2018. Secara umum materi kejurnalistikan disampaikan secara bergantian oleh tim pengabdi yaitu Abdul Wahab, M.S.I, Khoirul Muslimin, M.I.Kom, Murniati, M.S.I, dan Mahfudlah Fajrie, M.S.I. Materi yang disampaikan pada pelatihan ini adalah perbedaan dasar antara artikel dan berita, tips dan trik menulis berita, dan penulisan berita yang layak baca.

2. Materi Press Release

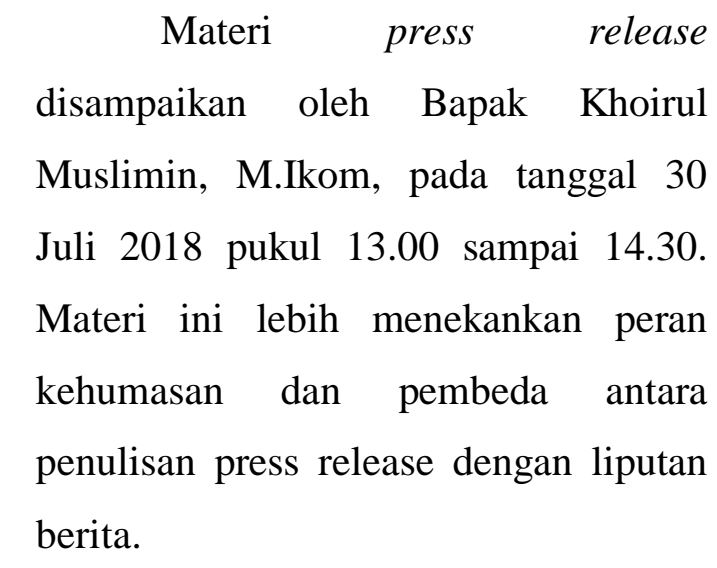

3. Pelatihan Layout dan Editing

Materi yang disampaikan adalah teknik layout pembuatan koran dinding dan teknik mengedit naskah yang akan 
diterbitkan di majalah dinding. Materi ini disampaikan oleh Bapak Khoirul Muslimin, M.I.Kom.

\section{PEMBAHASAN}

Hasil yang dicapai dari pelatihan menulis berita adalah para siswa bisa memahami teknik menulis jurnalistik media, paham kode etik jurnalistik dan mengetahui bagaimana teknik wawancara kepada narasumber dalam menggali sebuah berita. Peserta juga melakukan praktik wawancara dan menyarikan hasilnya dalam bentuk liputan.

Siswa peserta pelatihan diminta tim untuk terjun kelapangan menggali berita dan menemukan narasumber yang tepat. Sebelum peserta diminta terjun ke lapangan terlebih dahulu tim pengabdi membagi peserta 5 (lima) kelompok. Setiap kelompok didampingi pamong dari mahasiswa Fakultas Dakwah dan Komunikasi.

Adapun pembagian kelompok 1 (satu) didampingi pamong Firda Jauharin Kamaliyah, kelompok 2 (dua) didampingi pamong Ani Khikmawati, kelompok 3 (tiga) didampingi pamong Wiwit, kelompok 4 (empat) didampingi pamong Ahmad Rifai, kelompok 5 (lima) didampingi pamong Fitri Noor Ida.

Hasil dari sesi ini, peserta telah mampu dalam menyusun daftar pertanyaan yang berfungsi sebagai penggali informasi serta menuliskannya dalam bentuk reportase.

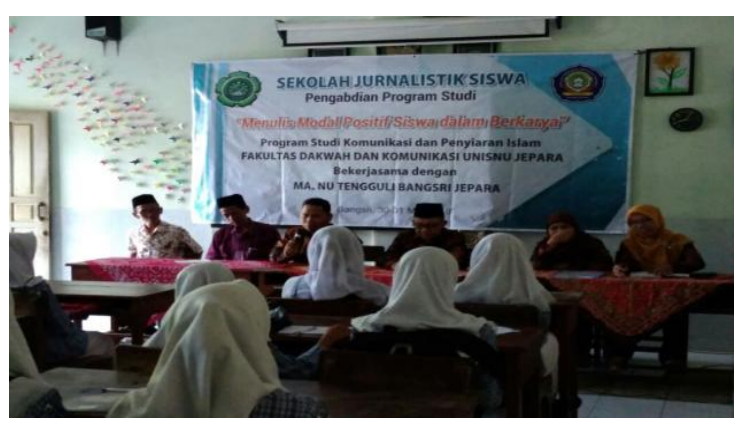

Gambar 2. Pelatihan Menulis Berita

Pelatihan penulisan press release menunjukkan bahwa para siswa mamahami dan mengetahui bagaimana etika menulis jurnalistik dan bagaimana cara membuat press release. Siswa juga memahami perbedaan press release dengan tulisan reportase. Siswa yang menjadi peserta memahami fungsi kehumasan dalam meningkatkan branding melalui berita pers (Farihanto, 2014).

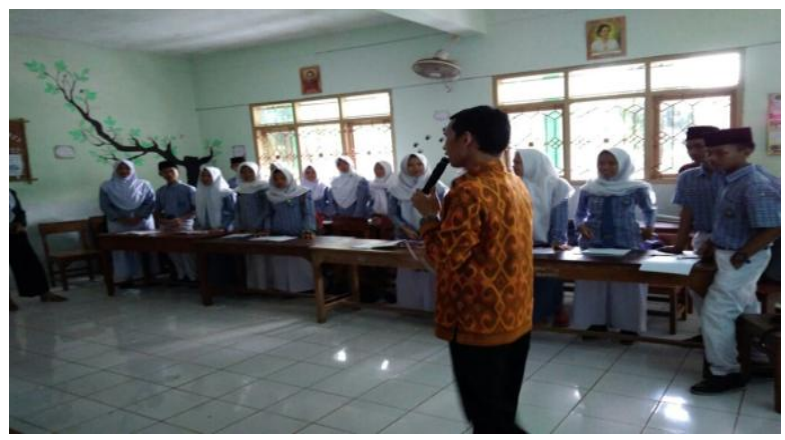

Gambar 3. Menyampaikan Materi Menulis Berita 


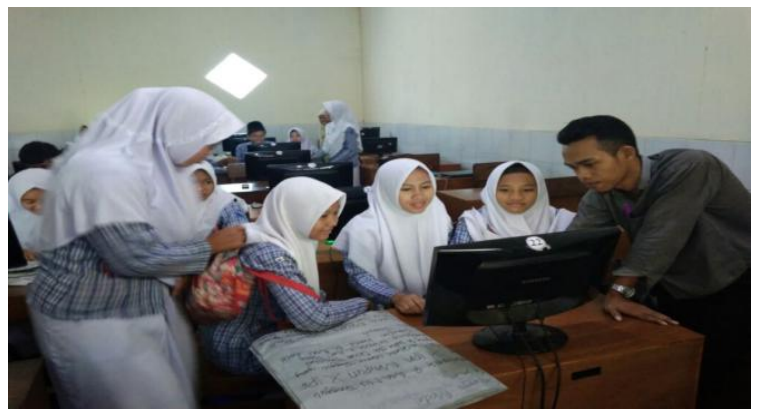

Gambar 4. Pendampingan praktik editing berita

Materi Layout pembuatan koran dinding dilakukan dengan cara peserta dikelompokan menjadi 6 (enam) di antaranya : (1) kelompok I didampingi oleh Firdaus Jauhartul Kamaliyah dan Umi Hindun; (2) kelompok II didampingi oleh Wiwid Endang Widiastuti; (3) kelompok III didampingi oleh Ani Khikmawati; (4) kelompok IV didampingi Ahmad Rifa'i; (5) kelompok V didampingi Ali Ridlo; dan (6) kelompok VI didampingi oleh Mastu'ah.

Tahap pertama, para siswa diminta untuk membuat tulisan atau nama koran dinding sesuai dengan kesepakatan kelompok. Nama koran dinding disertai dengan tagline dan alamat redaksi.

Tahapan kedua, para siswa diminta untuk memasukkan kontent berita yang telah dikerjakan pada pertemuan pertama disertai dengan dokumentasi hasil hunting.

Tahapan ketiga, hasil peserta dimintai untuk melengkapi konten koran dinding yang telah dibuat, dengan nenambahkan kontent artikel dan tips.
Kontent artikel dan tips bisa diperoleh melalui internet, dengan syarat mencantumkan sumbernya.

Tatap keempat, hasil layout koran dinding diprint dan dilakukan evaluasi hasil karya yang telah dihasilkan.

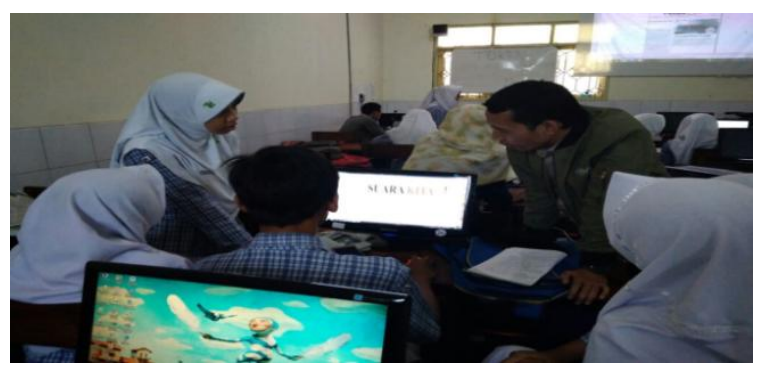

Gambar 5. Pendampingan Layout dan Editing

Keterlibatan aktif dari peserta dan tingkat pemahaman yang baik serta hasil dari praktik yang dilakukan oleh siswa menunjukkan bahwa materi-materi yang disampaikan oleh tim pengabdi dalam diserap dan diterapkan sebagai keberlanjutan program. Hal ini sejalan dengan beberapa pengabdian dan penelitian yang menunjukkan bahwa keterlibatan aktif peserta berkorelasi dengan tingkat pemahaman (Adnyana, 2012). Hasil karya siswa berupa liputan, press release, dan hasil editing naskah juga $\mathrm{d}\{$ Citation $\}$ itampilkan pada majalah dinding.

\section{SIMPULAN DAN SARAN}

Hasil kegiatan yang telah dilakukan menunjukkan para siswa bisa mencari 
berita di lapangan, selain itu para siswa bisa menentukan narasumber yang tepat dalam membuat karya jurnalistik dan mampu menulis berita. Selain itu, para siswa mampu melakukan proses layouting dan editing. Selanjutnya pembentukan redaktur majalah sekolah dan majalah sekolah.

Tindak lanjut yang dapat diusulkan adalah pihak madrasah memfasilitasi terbentuknya majalah sekolah agar pihak madrasah mendampingi lebih lanjut terbitnya majalah sekolah secara berkala setelah tim PKM menyelesaikan program pengabdian sekolah binaan ini.

\section{UCAPAN TERIMA KASIH}

Tim pelaksana pengabdian mengucapkan terima kasih kepada Kepala Madrasah Nahdlatul Ulama Tengguli dan siswa-siswi kelas XI yang telah menjadi mitra dalam pelaksanaan pengabdian ini, serta pihak terkait lain yang telah membantu selama kegiatan

\section{DAFTAR PUSTAKA}

Adnyana, G. P. (2012). Keterampilan Berpikir Kritis dan Pemahaman Konsep Siswa pada Model Siklus Belajar Hipotetis Deduktif. Jurnal Pendidikan dan Pengajaran, 45(3).
Anggraini, S. (2016). Budaya Literasi Dalam Komunikasi. WACANA, Jurnal Ilmiah Ilmu Komunikasi, 15(3), 264-279.

Farihanto, M. N. (2016). Teman tapi mesra humas dan wartawan (studi kasus strategi hubungan media di bidang humas dan protokoler universitas ahmad dahlan). Profetik: Jurnal Komunikasi, 7(2).

Fitryarini, I. (2017). Literasi Media Pada Mahasiswa Prodi Ilmu Komunikasi Universitas Mulawarman. Jurnal Komunikasi, $\quad 8(1), \quad$ 51-67. https://doi.org/10.24912/jk.v8i1.46

Gumilar, G. (2017). Literasi media: Cerdas menggunakan media sosial dalam menanggulangi berita palsu (HOAX) Oleh Siswa SMA. Jurnal Pengabdian Kepada Masyarakat, l(1).

Indonesia, R. (2003). Undang-undang Republik Indonesia nomor 20 tahun 2003 tentang sistem pendidikan nasional. Jakarta: Pemerintah Republik Indonesia.

Nopilda, L., \& Kristiawan, M. (2018). Gerakan Literasi Sekolah Berbasis Pembelajaran Multiliterasi Sebuah Paradigma Pendidikan Abad Ke21. JMKSP (Jurnal Manajemen, Kepemimpinan, Dan Supervisi Pendidikan), $3(2)$. 
https://doi.org/10.31851/jmksp.v3i

2.1862

Supratman, L. P., \& Wahyudin, A. (2017).

Digital Media Literacy to Higher

Students in Indonesia.

International Journal English

Literature and Social Sciences,

2(5). Diambil dari

https://ijels.com/detail/digital-

media-literacy-to-higher-students-

in-indonesia/

Suragangga, I. M. N. (2017). Mendidik

Lewat Literasi untuk Pendidikan

Berkualitas. Jurnal Penjaminan

Mutu, 3(2), 154-163.

https://doi.org/10.25078/jpm.v3i2.1

95

Wahid, A. (2014). Peran Wartawan Muslim dalam Kegiatan Dakwah.

Jurnal Dakwah Tabligh, 15(2), 259-269.

https://doi.org/10.24252/jdt.v15i2.3

53 